\title{
Evolutionary Psychology
}

www.epjournal.net - 2007. 5(3): 612-631

Original Article

\section{Sex Differences in Romantic Kissing Among College Students: An Evolutionary Perspective}

Susan M. Hughes, Department of Psychology, Albright College, Reading, PA 19612, USA Email: shughes@alb.edu (Corresponding author)

Marissa A. Harrison, Department of Social Sciences and Human Services, Borough of Manhattan Community College, The City University of New York, New York, NY, 10007, USA

Gordon G. Gallup, Jr., Department of Psychology, University at Albany, State University of New York, Albany, NY 12222, USA

Abstract: This study provides a descriptive account of kissing behavior in a large sample of undergraduate college students and considers kissing in the context of both short-term and long-term mating relationships. Kissing was examined as a mate assessment device, a means of promoting pair bonds, and a means of inducing sexual arousal and receptivity. A total 1,041 college students completed one of three questionnaires measuring kissing preferences, attitudes, styles, and behaviors. Results showed that females place more importance on kissing as a mate assessment device and as a means of initiating, maintaining, and monitoring the current status of their relationship with a long-term partner. In contrast, males place less importance on kissing, especially with short-term partners, and appear to use kissing to increase the likelihood of having sex. The results suggest that kissing may play an important role as an adaptive courtship/mating ritual.

Keywords: kissing, sex differences, sexual behavior, pair bonding, mate assessment

\section{Introduction}

Kissing between sexual and/or romantic partners occurs in over 90 percent of human cultures (Eibl-Eibesfeldt, 1970; Fisher, 1992). Even in cultures where kissing is nonexistent or condemned, sex partners may blow in each other's faces, lick, suck, or rub their partner's face prior to intercourse (Ford and Beach, 1951). Some non-human animals appear to engage in kissing-like behaviors, as well (Geer, Heiman, and Leitenberg, 1984). For instance, de Waal (2000) claims that bonobos regularly engage in bouts of deep tongue kissing. Although kissing is a widespread practice among humans, few investigators have 


\section{Kissing}

attempted to assess the adaptive significance of kissing behavior. In the present study, we investigated sex differences in kissing among college students in light of some prevailing theories about why kissing may be adaptive. We also considered kissing behavior in the context of both long-term and short-term mating.

\section{Hypothesis 1: Kissing as a Mate Assessment Device}

Some theorists suggest that kissing can be an investigatory process that places individuals in close proximity to each other in order to smell, taste, and assess other features that may contribute to making mate assessments (Fisher, 1983). Studies have shown that the taste and the breath of an individual's mouth can be indicative of underlying health problems (Durham, Malloy, and Hodges, 1993; Hoshi, Yamano, Mitsunaga, Shimizu, Kagawa, Ogiuchi, 2002; Rosenberg, 2002; Service, 1998). In addition to information provided by olfactory cues during kissing, there may be a transfer of sebum from the suction of the skin surface around the mouth and the surfaces of the buccal, oral, and gingival mucosae inside the mouth. The exchange of sebum during kissing could mediate pheromonal and hormonal information (Montagna and Parakkal, 1974; Nicholson, 1984).

We hypothesize that females will place a greater importance on kissing for making assessments about the health and quality of a potential mate, since females tend to practice more discriminative mating due to their limited reproductive potential and greater parental investment (Trivers, 1972). In addition, females have a heightened sense of olfactory and taste detection compared to males and this greater chemosensory acuity becomes even more pronounced during ovulation (Doty, Shaman, Applebaum, Giberson, Siksorski, and Rosenberg, 1984; Pause, Sojka, Bernfried, Krauel, Fehm-Wolfsdorf, and Ferstl, 1996). Such detection enhancement may put females in a better position to use chemosensory cues during kissing to assess potential mates.

Men, being the less investing sex, are expected to be less discriminating when seeking short-term mates (Symons, 1979). However, features that signal a female's fertility are often important to males when making assessments of both short- or long-term mates (Symons, 1979). We suspect that certain physical features, such as a female's body weight, may influence a male's decision to kiss a partner. In addition, both breath odor and saliva may provide cues to a woman's fertility. For instance, the rise in estrogen that occurs near the onset of menstruation triggers the shedding of body cells, including cells present in mouth, creating a condition that is ideal for bacterial growth which may cause a woman to have unpleasant breath near her menstrual period (McCann and Bonci, 2001). It is also thought that changes in estrogens may lead to an increase in sulfur compounds in the mouth that can cause unpleasant odors (Tonzetich, Preti, and Huggins, 1978). Furthermore, females produce other distinctive, yet odorless molecules in saliva while ovulating (Fullagar, 2003) that might be detected by males during kissing.

However, given that males are less sensitive to chemosensory cues, making such assessments of a female's fertility by means of kissing may be more difficult, and we suggest that males may require greater salivary exchange to facilitate assessments of female fertility and, for that reason, prefer wetter, open mouth, tongue kisses. 


\section{Kissing}

\section{Hypothesis 2: Kissing Induces Bonding}

Nicholson (1984) contends that kissing may be a mechanism by which pheromones and sebum are exchanged to induce bonding. Accepting a kiss may be indicative of one's commitment to that person (Zahavi and Zahavi, 1997, p. 218) and a sign that one is willing to accept the risk of contracting an illness. Kissing can even trigger fatal allergic responses to food (Hallett, Haapanen, and Teuber, 2002). In addition, kissing may be used by both sexes as a reconciliation gesture and a way to reestablish a bond after an argument or a fight. Furthermore, activities causing sexual excitement, such as kissing, may increase levels of oxytocin in both sexes, which has been shown to play a role in interpersonal bonding (Carter, 1992).

Gulledge, Gulledge, and Stahmann (2003) found that kissing on the lips was rated by both college men and women as being more intimate than "cuddling," "holding hands," "hugging," "caressing," "stroking," "massages," "backrubs,” and "kissing on the face.” In addition, the amount of reported kissing between partners is directly proportional to relationship satisfaction (Gulledge, et al., 2003), and both sexes rate kissing as one of the most highly romantic acts a couple can engage in (Tucker, Marvin, and Vivian, 1991). If kissing serves to create a bond between partners, one would not expect to see kissing in situations where bonding is not wanted, such as in commercial sex or casual sexual encounters. For instance, prostitutes often refuse to kiss clientele, because kissing reflects a "genuine desire and love for the other person" (Brewis and Linstead, 2000, p. 90) and their refusal to kiss clients is thought to be an emotional distancing technique (Arnold and Barling, 2003, p.15).

We hypothesize that kissing functions to promote, maintain, and assess the status of bonding by both sexes, especially in long-term relationships. On the other hand, when it comes to short-term mating, men may avoid women who demand serious commitments or investments before consenting to sex (Buss and Schmitt, 1993). Therefore, men may place less importance on kissing with short-term mates to avoid creating a bond. The benefits afforded to females who pursue short-term mating strategies are different than those for males. Reasons why females engage in short-term mating may include gaining resources (Smith, 1984; Symons, 1979), achieving genetic diversity among their children (Smith, 1984), mate switching (Smith, 1984; Symons, 1979), or current mate manipulation (Symons, 1979). In these instances, creating a bond with a short-term mate may be more likely, so the idea of kissing and bonding in a short-term relationship could be more important to females.

\section{Hypothesis 3: Kissing Increases Sexual Arousal and Receptivity}

Kissing can also be viewed as an activity that increases sexual arousal and receptivity. There is evidence that males, in particular, use kissing as an attempt to "seduce" romantic partners and kissing may be used by men as a strategy to gain sexual access to females. Studies of date rape suggest that men feel more entitled to force sexual intercourse if they have been kissing their partner (Abbey, McAuslan, Zawacki, Clinton, and Buck, 2001, p. 787; Goodchilds and Zellman, 1984; Koss, 1988). Muehlenhard and Cook (1988) found that women were more likely than men to have been kissed against their wishes. Moreover, Christopher (1988) reported that $57 \%$ of college-aged women had been pressured into kissing by physical attempts, verbal coercing or threats, or actual force in an attempt to make them more sexually receptive. Forced kissing is also reported in other 
cultures. In a sample of university students in India, 33\% of women and $27 \%$ of men acknowledged being forced to kiss by a romantic partner (Waldner, Vaden-Goad, and Sikka, 1999). Likewise, in a study of Chinese college students, $20.3 \%$ of the women reported having been in a dating situation where they had been kissed against their will, and $8.2 \%$ of the men reported that they had kissed a woman against her will (So-Kum Tang, Critelli, and Porter, 1995). One speculative possibility is that men may unwittingly use kissing to introduce substances such as hormones or proteins into women's mouths, thereby manipulating their mating psychology, and perhaps making them more likely to have sex. It is also possible that males may perceive a greater wetness or salivary exchange during kissing as an index of the female's sexual arousal/ receptivity, similar to the act of sexual intercourse.

We hypothesize that in long-term relationships, both sexes will place equal importance on kissing, especially with saliva exchange, to facilitate sexual arousal and receptivity. On the other hand, when it comes to short-term relations, females may be less inclined to kiss and exchange saliva if they choose not to have intercourse. We also hypothesize that both sexes may be more jealous if they know their partner kissed another person with tongue contact, since this style of kissing is associated with the intent to arouse and could therefore lead to sexual infidelity.

The present study provides a descriptive account of kissing behavior by measuring attitudes, preferences, and sex differences among a large sample of college students, and considers kissing within the context of both short-term and long-term mating situations. Specifically, we examined several features of kissing behavior that include different kissing styles (i.e., open mouth kisses, wetness, tongue contact), kissing and sexual behavior, bonding and relationship status, and the attractiveness and physical traits of kissing partners.

\section{Materials and Methods}

A series of three studies approved by the local Institutional Review Board were conducted using anonymous questionnaires administered to students enrolled in psychology courses at the University at Albany, State University of New York. A total of 1,041 respondents completed one of three anonymous questionnaires in a classroom setting. In order to assure that responses were based, in part, on first-hand experience, participants who indicated that they had never romantically kissed another person were excluded for the analyses. Since we were examining opposite sex relations as it relates to mating strategies, we only included those who indicated a preference for kissing "only" or "mostly" members of the opposite sex.

\section{Study 1}

\section{Method}

Respondents were asked to report their attitudes and experiences regarding several facets of kissing behavior, including short- versus long-term partner kissing, tongue kissing, and kissing with respect to sexual behavior. The first questionnaire was administered to 501 (175 males and 326 females) undergraduate students. Of the participants, $93.6 \%$ fell in the range of $18-24$ years of age, while the remaining $6.4 \%$ fell in 


\section{Kissing}

the "25 and above" category. Two participants who reported having never kissed were excluded from the study and only those who had a preference for kissing "only" or "mostly" members of the opposite sex were included for the analyses, yielding a sample of 470 (162 males and 308 females). Of those who reported having experience with romantic kissing, 10\% indicated having kissed 1-2 partners, 15\% 3-5 partners, 23\% 6-10 partners, 27\% 11-20 partners, and 25\% kissed 21 or more partners. There were no sex differences in terms of number of kissing partners, $t(468)=-0.48, p=63$, $n s$. Males $(M=14.1, S D=$ 2.4) and females $(M=14.2, S D=2.0)$ also did not differ with regards to the age of their first romantic kiss, $t(453)=-0.62, p=.54, n s$. Fifty-three percent of the respondents indicated that they were currently in a committed, long-term relationship.

\section{Results}

\section{Breath and Taste}

Respondents were asked to rate the importance of a person's breath when deciding to kiss or continue to kiss someone based on a five point Likert scale $(0=$ not at all important, 1 = slightly, 2 = somewhat, $3=$ very, and $4=$ extremely important $)$. Females $(M$ $=3.09, S D=0.82$ ) rated a person's breath as more important when deciding to kiss or continue to kiss someone than did males $(M=2.88, S D=0.88), t(465)=-2.56, p=.011$, significant using a Bonferroni correction, $\eta^{2}=.014$. Similarly, females $(M=3.00, S D=$ 0.87) rated the taste of someone's mouth as more important when deciding to continue to kiss someone than did males $(M=2.67, S D=0.87), t(465)=-3.79, p=.000$, using a Bonferroni correction, $\eta^{2}=.030$.

\section{Kissing and Sexual Behavior}

Participants were asked if they would have sex with someone without kissing. As shown in Figure 1, whereas over half of the males (52.8\%) indicated that they would have sex without kissing, only about one in seven females would consider having sex with someone without kissing them first $(14.6 \%),\left[X^{2}(1, N=446)=72.38, p<.000\right]$.

Respondents answered questions regarding the importance of kissing before, during, and after sexual intercourse with a committed, long-term partner and a casual, short-term partner based on a five-point Likert scale ( 0 = not at all important, $1=$ slightly, 2 = somewhat, 3 = very and 4 = extremely important). A 2 X 2 X 3 mixed design ANOVA was conducted with sex of respondent (male/female) as the between-subject factor, and relationship status (long-or short-term partner) and time surrounding sex (before sex/during sex/after sex) as the within-subject factors. There was a main effect for sex of respondent, with females $(M=2.47, S E=0.05)$ rating kissing as more important than males across all situations $(M=2.04, S E=0.06), F(1,337)=30.83, p=.000$, partial $\eta^{2}=.084$. There was a main effect for relationship status, with kissing rated as more important across all situations with committed, long-term partners $(M=2.75, S E=0.04)$ than with short-term partners ( $M$ $=1.76, S E=0.05), F(1,337)=300.77, p=.000$, partial $\eta^{2}=.472$. There was also a main effect for the importance of kissing with respect to time surrounding intercourse (before sex $M=2.62, S E=0.04$, during sex $M=2.20, S E=0.05$, and after sex $M=1.94, S E=0.05$ ), $F(2,337)=121.27, p=.000$, partial $\eta^{2}=.265$. Furthermore, as seen in Figure 2, there was an interaction between relationship status and time of kissing with respect to intercourse, $F(2,337)=38.84, p=.000$, partial $\eta^{2}=.103$. 
Figure 1. Differences in the willingness to have sex without kissing for males $(n=144)$ and females $(n=$ 302).

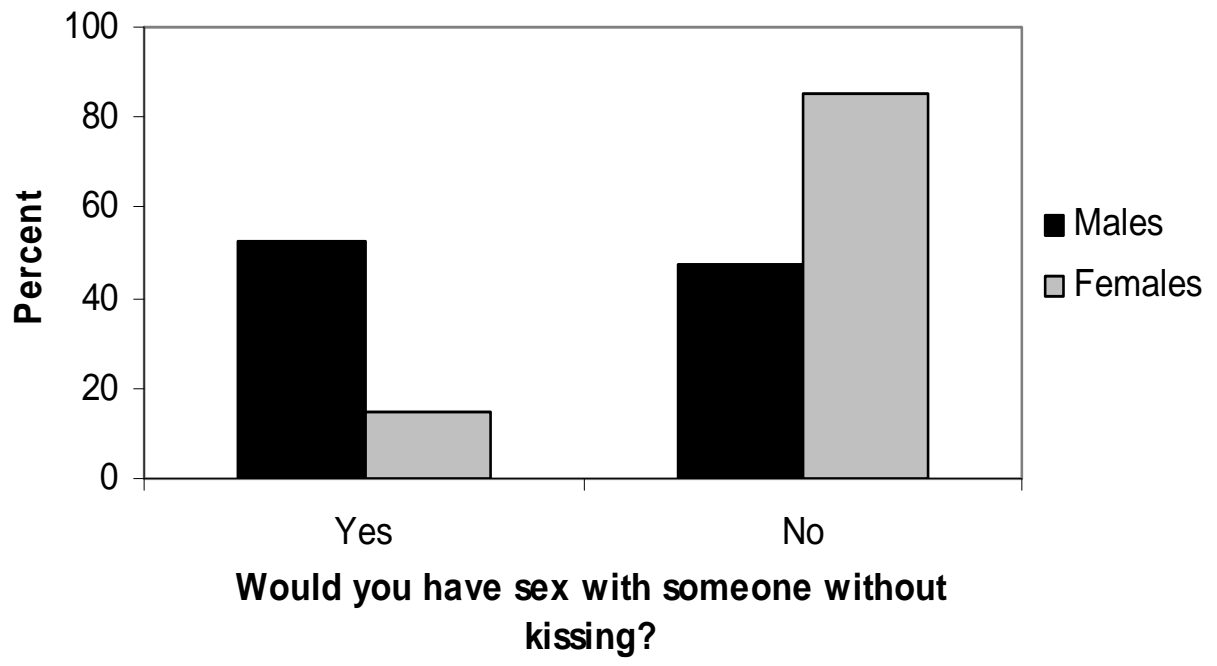

Participants were asked how likely kissing would lead to sex when involved with a short- or long-term partner, with response choices scaled as $0=$ never, $1=$ sometimes, and 2 = always. A 2 (sex of respondent) X 2 (relationship status) mixed design ANOVA revealed a main effect for sex of respondent, with males $(M=1.02, S E=0.03)$, feeling that kissing should lead to sex more often than females $(M=0.78, S E=0.02), F(1,454)=$ 45.61, $p=.000$, partial $\eta^{2}=.091$. There was also a main effect for relationship status; respondents thought that kissing should lead to sex more often with a long-term partner ( $M$ $=1.03, S E=0.02)$, than with a short-term partner $(M=0.80, S E=0.02), F(1,454)=$ 102.11, $p=.000$, partial $\eta^{2}=.184$. In addition, there was a significant interaction between sex of respondent and relationship status $F(1,454)=41.19, p=.000$, partial $\eta^{2}=.083$. Females thought kissing should lead to sex more with a long-term partner $(M=0.98, S D=$ $0.33)$ than with a short-term partner $(M=0.56, S D=0.55)$, whereas males felt that kissing should lead to sex to the same degree with both a long-term $(M=1.07, S D=0.34)$ and a short-term partner $(M=0.97, S D=0.50)$. 
Figure 2. The importance of kissing before, during, and after sex with a long-term partner or short-term partner rated on a five-point Likert scale $(1=$ not at all important, $1=$ slightly $2=$ somewhat, $3=$ very and $4=$ extremely important).

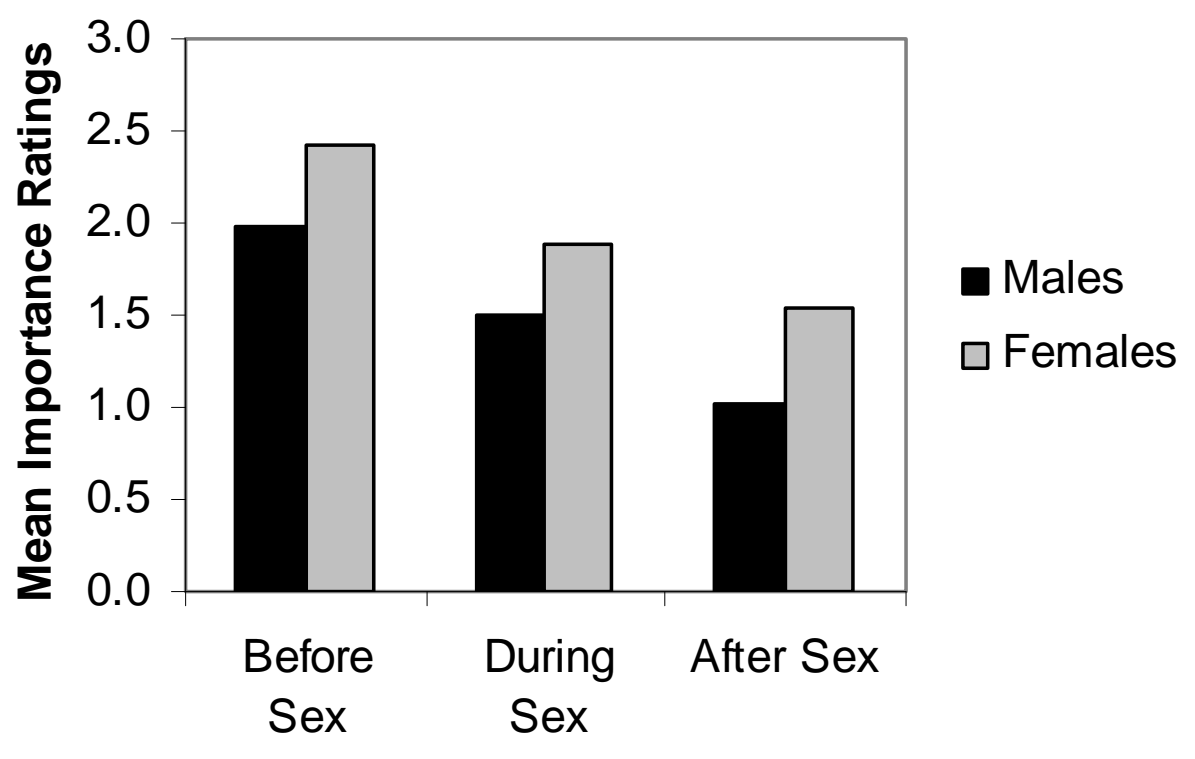

\section{Kissing In Relation to Sex}

\section{Bonding and Relationships}

Participants were asked to rate the importance of kissing at the beginning and during the latter parts of a relationship using a five-point Likert scale $(0=$ not at all important, 4 = extremely important). A 2 (sex of respondent) X 2 (relationship duration) mixed design ANOVA was conducted that showed a main effect for sex of respondent, where females $(M=2.78, S E=0.04)$, rated kissing as being overall more important than did males $(M=2.45, S E=0.06), F(1,455)=18.89, p=.000$, partial $\eta^{2}=.040$. There was a main effect for relationship duration, where respondents thought that kissing during the beginning of a relationship $(M=2.67, S E=0.05)$ was more important than during the latter parts of the relationship $(M=2.56, S E=0.05), F(1,455)=4.94, p=.027$, partial $\eta^{2}=.011$. There was also a significant interaction between sex of respondent and relationship duration, $F(1,455)=15.45, p=.000$, partial $\eta^{2}=.011$. As shown in Figure 3 , for males, the importance of kissing decreased as the relationship progresses over time (beginning $M=$ 2.60, $S D=0.89$ and latter $M=2.30, S D=1.00), t(151)=3.50, p=.001$, whereas the importance of kissing remained relatively constant throughout the relationship for females (beginning $M=2.74, S D=0.90$ and latter $M=2.82, S D=0.91$ ), $t(304)=-1.54, p=.124$, $n s$. 
Figure 3. Based on a five-point Likert scale $(0=$ not at all important, $1=$ slightly $2=$ somewhat, $3=$ very and 4 = extremely important), ratings of kissing importance during the beginning of the relationship as compared to latter phases for males $(n=153)$ and females $(n=307)$.

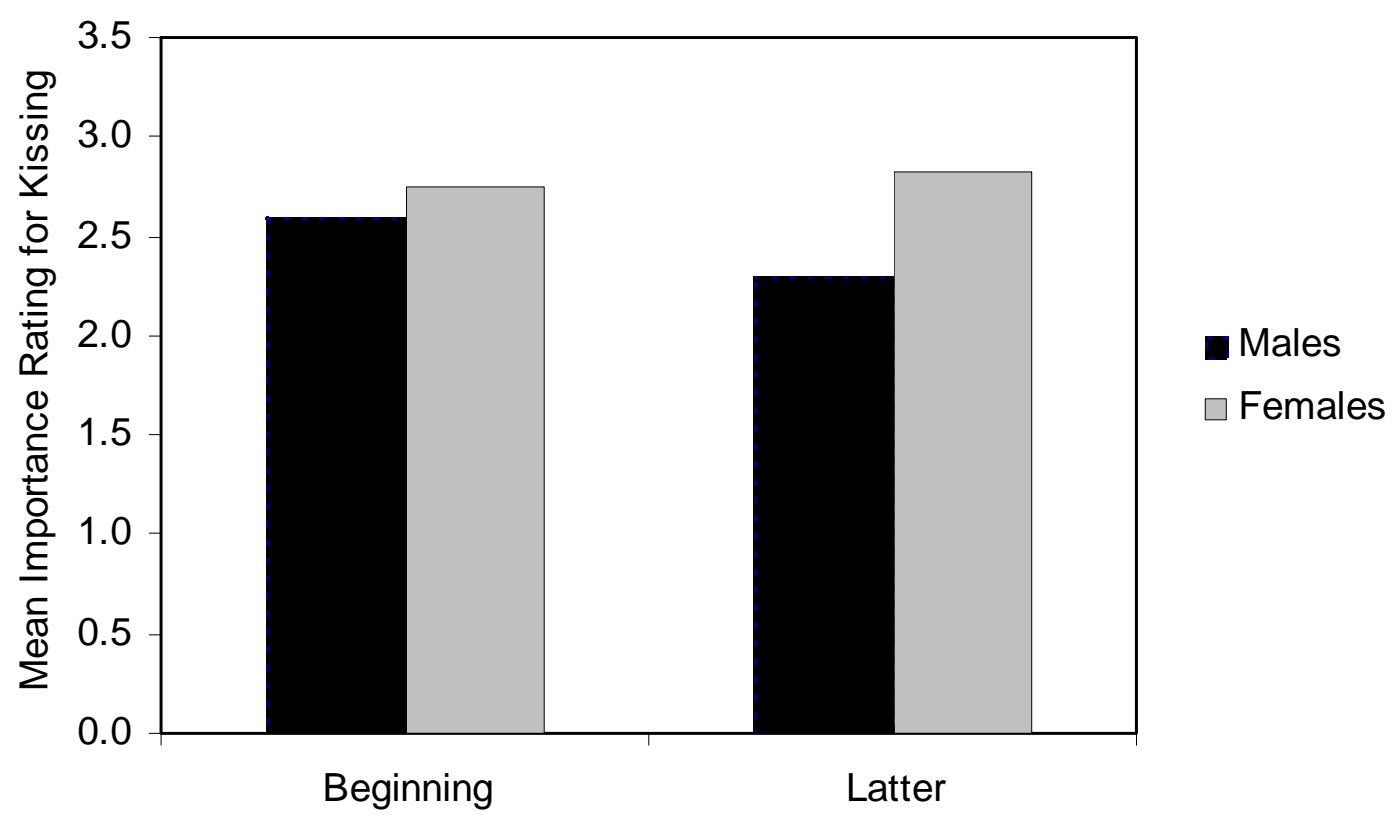

Relationship Duration

When it comes to kissing as a form of reconciliation, significantly more males (70.1\%) thought kissing a romantic partner could end a fight than did females (58.0\%), [ $X^{2}$ $(1, N=477)=5.75, p=.016]$. However, the majority of males $(69 \%)$ and females $(67 \%)$ felt that just because someone was a good kisser would not be a reason to start a relationship $\left[X^{2}(1, N=429)=0.13, p=.716, n s\right]$.

\section{Salivary Exchange}

Respondents were asked how "wet" they preferred their kisses when kissing a short- or long-term partner, where responses were scaled as $0=$ totally dry, $1=$ slightly moist, 2 = somewhat wet, 3 = very wet, and $4=$ extremely wet. Based on a 2 (sex of respondent) X 2 (relationship status) ANOVA, there was a main effect for sex of respondent, with males $(M=1.83, S E=0.05)$ preferring overall wetter kisses than females $(M=1.38, S E=0.03), F(1,418)=65.76, p=.000$, partial $\eta^{2}=.136$. There was a main effect for relationship status, where respondents preferred wetter kisses when kissing a long-term partner $(M=1.69, S E=0.03)$ than a short-term partner $(M=1.52, S E=0.03)$, $F(1,418)=30.26, p=.000$, partial $\eta^{2}=.067$. There was also a significant interaction between sex of respondent and relationship status $F(1,418)=5.56, p=.019$, partial $\eta^{2}=$ .013. Males preferred wet kisses with both long-term $(M=1.88, S D=0.63)$ and short term partners $(M=1.79, S D=0.66) t(139)=1.91, p=.060$, whereas females preferred wet 


\section{Kissing}

kisses with long-term partners more $(M=1.50, S D=0.57)$ than with short-term partners $(M=1.26 S D=0.62), t(279)=6.82, p=.000$.

Participants were also asked to rate how much tongue contact they thought should be involved in a romantic kiss when kissing a long-term as opposed to a short-term partner. Responses ranged on a five point Likert scale from $0=$ not at all involved to $4=$ extremely involved. There was a main effect for sex of respondent, with males $(M=2.22, S E=0.08)$ preferring more tongue contact than females $(M=2.00, S E=0.06), F(1,425)=4.44, p$ $=.036$, partial $\eta^{2}=.010$. There was a main effect for relationship status, with respondents preferring more tongue contact with long-term $(M=2.35, S E=0.08)$, than short-term partners $(M=1.86, S E=0.05), F(1,425)=32.56, p=.000$, partial $\eta^{2}=.071$. There was also a significant interaction between sex of respondent and relationship status, $F(1,425)=$ 6.61, $p=.010$, partial $\eta^{2}=.015$. Whereas both males $(M=2.35, S D=0.72)$ and females $(M$ $=2.36, S D=1.93$ ) preferred more tongue contact with long-term partners, $t(444)=.002, p$ $=.998, n s$, when it came to tongue contact with short-term partners, males $(M=2.08, S D=$ 0.81) preferred more tongue contact than females $(M=1.64 S D=0.90), t(428)=4.85, p=$ .000 .

There were no sex differences in preferences for open or closed mouth kisses with long-term partners; $65.6 \%$ of males and $64.7 \%$ of females preferred open mouth kisses when kissing a long-term partner, $\left[X^{2}(2, N=446)=.048, p=.976, n s\right]$. However, when kissing a short-term partner, more males (55.6\%) preferred open mouth kisses than females $(36.8 \%),\left[X^{2}(2, N=411)=21.70, p=.000\right]$.

\section{Study 2}

\section{Method}

The second study was undertaken as an elaboration and partial replication of the first. The second questionnaire was administered to an additional 273 undergraduate students (56 males and 217 females). Most (93.4\%) of the participants were within the 1824 age-range, with the remainder being above age 25. Three participants who reported never kissing were excluded from analyses and only those who indicated a preference for kissing "only" or "mostly" the opposite sex were included, yielding a sample of 257 (49 males and 208 females). Of the participants who reported kissing, 11\% had kissed 1-2 partners, 21\% 3-5 partners, 25\% 6-10 partners, 23\% 11-20 partners, and 20\% kissed 21 or more partners. There was no sex differences with regards to how many different partners respondents had kissed $t(254)=-0.69, p .494, n s$. Sixty percent indicated that they were currently in a committed, romantic relationship.

\section{Results}

\section{Kissing and Sexual Behavior}

Participants were asked how likely they would be to have sex without kissing in order to clarify the distinction between a committed long-term relationship versus a shortterm casual sexual encounter. Responses were recorded on an interval scale from $0=$ never to 4 = always. A 2 (sex of respondent) X 2 (relationship status) ANOVA was conducted. There was a main effect for relationship status, with respondents indicating that they would be more likely to have sex with a short-term partner $(M=1.24, S E=0.09)$ without kissing 


\section{Kissing}

than with a long-term partner $(M=0.80, S E=0.08), F(1,197)=28.51, p=.000$, partial $\eta^{2}$ $=.126$. There was also a significant interaction between sex of respondent and relationship status $F(1,197)=10.94, p=.001$, partial $\eta^{2}=.053$. Males were more likely to have sex without kissing a short-term partner $(\mathrm{M}=1.51, \mathrm{SD}=1.14)$ than were females $(M=0.97$, $S D=0.98), t(204)=2.57, p=.011$, whereas the likelihood of having sex without kissing a long-term partner was similar for males $(M=0.79, S D=1.00)$ and females $(M=0.80, S D$ $=0.84), t(237)=0.24, p=.811, n s$.

Questions about whether kissing should lead to sex when involved with a shortterm or long-term partner were asked again to extend the frequency choices to a five-point Likert scale $(0=$ never to $4=$ always $)$. Replicating the findings on the first questionnaire, a 2 (sex of respondent) X 2 (relationship status) mixed design ANOVA showed a main effect for sex of respondent; males $(M=2.30, S E=0.11)$ thought kissing should lead to sex more often than females $(M=1.66, S E=0.06), F(1,215)=25.57, p=.000$, partial $\eta^{2}=.106$. There was also a main effect of relationship status, where respondents thought kissing should lead to sex more often with a long-term $(M=2.14, S E=0.07)$, than with a shortterm partner $(M=1.83, S E=0.08), F(1,215)=13.11, p=.000$, partial $\eta^{2}=.057$. There was a significant interaction between sex of respondent and relationship status $F(1,215)=$ $11.28, p=.001$, partial $\eta^{2}=.050$. Although males thought kissing should lead to sex with a long-term partner $(M=2.31, S D=0.87)$ as much as with a short-term partner $(M=2.29$, $S D=0.99), t(41)=0.14, p=.891, n s$, females thought kissing should lead to sex more often with a long-term $(M=1.97, S D=0.84)$ than a short-term partner $(M=1.34, S D=$ 0.96), $t(174)=8.05, p=.000$.

We also asked which sex generally initiates kissing before and after sex. Response options were presented on a five-point categorical scale where $0=$ only men, $1=$ mostly men, 2 = men and women equally, $3=$ mostly women, $4=$ only women. The majority of males (51\%) and females (59\%) thought that men and women are equally likely to initiate kissing before sex $\left[X^{2}(4, N=248)=6.99, p=.136, n s\right]$. In contrast, the majority of males (70\%) and females (64\%) agreed that women are more prone to initiate kissing after sex, $\left[X^{2}(4, N=242)=12.25, p=.016\right]$.

Based on a five point Likert scale ranging from $0=$ never to $1=$ always, participants were asked how often they wanted to kiss either their long- or short-term partner after experiencing an orgasm. A 2 (sex of respondent) X 2 (relationship status) ANOVA revealed a main effect for relationship status. Respondents wanted to kiss a long-term partner more often after having an orgasm $(M=2.77, S E=0.09)$ than a short-term partner, $(M=1.69 S E=0.09), F(1,166)=146.70, p=.000$, partial $\eta^{2}=.469$. There were no significant sex differences and no significant interaction between sex of respondent and relationship status.

\section{Bonding and Relationships}

Participants were asked the degree to which they thought kissing after sexual intercourse creates a bond between them and their long- or short-term partner (based on a five point Likert scale of $0=$ not at all to $4=$ extremely so). A 2 (sex of respondent) X 2 (relationship status) ANOVA revealed a main effect for relationship. Both sexes thought that a greater bond was created by kissing after sex with a long-term partner $(M=2.62$, SE $=0.08)$ than with a short-term partner, $(M=1.37, S E=0.08), F(1,201)=205.39, p=.000$, 


\section{Kissing}

partial $\eta^{2}=.505$. There were no significant sex differences and no interaction between sex of respondent and relationship status factors.

The participants were asked to rate how emotionally close they felt after kissing a long- or short-term partner on a five point Likert scale of $0=$ not at all closer to $4=$ extremely closer. A 2 (sex of respondent) X 2 (relationship status) ANOVA was conducted. Although there was no sex difference, the results showed a main effect for relationship status. Respondents felt emotionally closer to their long-term partner $(M=2.79, S E=0.07)$ after kissing than to their short-term partner, $(M=1.70, S E=0.08), F(1,217)=172.86, p=$ .000 , partial $\eta^{2}=.443$. There was no a significant interaction between sex of respondent and relationship status factors.

\section{Salivary Exchange}

Participants were asked to indicate their preference for tongue contact during a first kiss (based on a Likert scale of $0=$ no tongue and $4=$ a lot of tongue). There was a main effect for sex of respondent, with males $(M=2.49, S E=0.13)$, preferring more tongue contact than females $(M=2.09, S E=0.06), F(1,224)=7.48, p=.007$, partial $\eta^{2}=.032$. There was also a main effect for relationship status, with respondents preferring more tongue contact with a short-term partner $(M=2.41, S E=0.10)$ than a long-term partner ( $M$ $=2.17, S E=0.08), F(1,224)=4.41, p=.097$, partial $\eta^{2}=.019$. However, there was no significant interaction.

How much tongue contact was preferred when kissing a long- or short-term partner before having sex was assessed using a five point Likert scale of $0=$ no tongue contact to 4 = a lot of tongue contact. A 2 (sex of respondent) X 2 (relationship status) ANOVA revealed a main effect for relationship. Before having sex, respondents preferred more tongue contact when kissing a long-term partner $(M=2.73, S E=0.09)$ than a short-term partner, $(M=2.55, S E=0.09), F(1,189)=4.84, p=.029$, partial $\eta^{2}=.025$. There were no significant sex differences and no significant interaction between sex of respondent and relationship status factors.

\section{Attractiveness and Kissing}

Respondents rated how willing they would be to kiss or have sex with someone they were not attracted to on a Likert scale of $0=$ never and $4=$ always. A 2 (sex of respondent) X 2 (activity) ANOVA showed a main effect for sex of respondent. Males ( $M$ $=1.13, S E=0.10$ ) were more willing to kiss or have sex with someone they were not attracted to than females $(M=0.57, S E=0.05), F(1,241)=25.57, p=.000$, partial $\eta^{2}=$ .096. But respondents of both sexes were more willing to kiss someone they are not attracted to $(M=0.97, S E=.006)$, than to have sex with someone they are not attracted to $(M=0.74, S E=0.06), F(1,241)=14.31, p=.000$, partial $\eta^{2}=.056$. There was a significant interaction between sex of respondent and these activities, $F(1,241)=20.63, p=.000$, partial $\eta^{2}=.079$. When comparing responses to both questions, post hoc paired-samples $t$ tests revealed that for males there was no difference in likelihood of kissing someone $(M=$ $1.11, S D=0.91)$ and having sex with someone $(M=1.15, S D=1.2)$ they were not attracted to, $t(44)=-.340, p=.736$, whereas females were less likely to have sex with someone $(M=$ $.33, S D=0.61)$ they were not attracted to than to kiss them $(M=.81, S D=0.73), t(197)=$ 10.31, $p=.000, \eta^{2}=.350$. 


\section{Kissing}

\section{Study 3}

\section{Methods}

The third study examined the perceived importance of kissing practices, attitudes toward kissing, and an assessment of kissing partners. This questionnaire was completed by another sample of 267 undergraduate students (71 males and 196 females), 92.8\% were in the age range of 18-24 with the remainder being 25 and or above. All participants reported having experienced romantically kissing and only those who indicated a preference for kissing "only" or "mostly" the opposite sex were included for the analysis, yielding a sample of 250 (69 males and 181 females). Of the participants, 12\% reported kissing 1-2 partners, 21\% 3-5 partners, 28\% 6-10 partners, 23\% 11-20 partners, and 16\% kissed 21 or more partners. Sixty-one percent indicated that they were currently in a committed romantic relationship.

\section{Results}

\section{Kissing and Sexual Behavior}

Participants were asked if they would want to have sex with someone who is a bad kisser, based on a 5-point Likert scale from $1=$ not at all to $4=$ extremely likely. As shown in Figure 4, males $(M=2.23, S D=0.87)$ were much more likely than females $(M=1.24$, $S D=0.88)$ to have sex with someone who was a bad kisser, $t(232)=7.68, p=.000$, significant using a Bonferroni correction, $\eta^{2}=.203$.

Participants were asked whether they would kiss someone that they knew only wanted to have sex and did not want a relationship. Based on a five point Likert scale from $0=$ not at all to $4=$ extremely likely, males $(M=2.53, S D=1.28)$ were more likely to have sex with someone that did not want a relationship than were females $(M=0.78, S D=0.90)$, $t(239)=11.87, p=.000$, significant using a Bonferroni correction, $\eta^{2}=.369$. Males $(M=$ $2.20, S D=1.18)$ were also more likely than females $(M=1.07, S D=1.14)$ to kiss someone that they wanted to have sex with and did not want to have a relationship with, $t(237)=$ $6.75, p=.000$, significant using a Bonferroni correction, $\eta^{2}=.161$.

As shown in Table 1, when asked to rate which factors are important for a good kiss, several sex differences emerged. More males than females indicated that a good kiss is one where their partner lets them initiate tongue contact, where kissing leads to sex, and their partner makes moaning noises. No other features showed significant sex differences.

\section{Salivary Exchange and Jealousy}

Jealousy was measured on a five point Likert scale $(0=$ not at all jealous to $4=$ extremely jealous) in response to a hypothetical situation where the respondent discovers that their long-term partner kissed someone of the opposite sex on the lips with either tongue or no tongue contact. A 2 (sex of respondent) X 2 (tongue contact) ANOVA revealed a main effect for sex of respondent, with females $(M=3.23$, $S D=0.08)$ showing more jealousy than males $(M=2.60, S D=0.13), F(1,163)=17.50, p=.000$, partial $\eta^{2}=$ .097. There was also a main effect for tongue contact, with respondents showing more jealousy when their partner kissed someone else using tongue $(\mathrm{M}=3.15, \mathrm{SD}=0.08)$ as compared to no tongue contact $(M=2.68, S D=0.09), F(1,163)=53.70, p=.000$, partial $\eta^{2}=.248$. There was no significant interaction. 


\section{Kissing}

Figure 4. Based on a five-point Likert scale (where $0=$ not at all likely and $4=$ extremely likely), the mean ratings of the likelihood of having sex with someone who is a bad kisser for males $(n=63)$ and females $(n=$ 171).

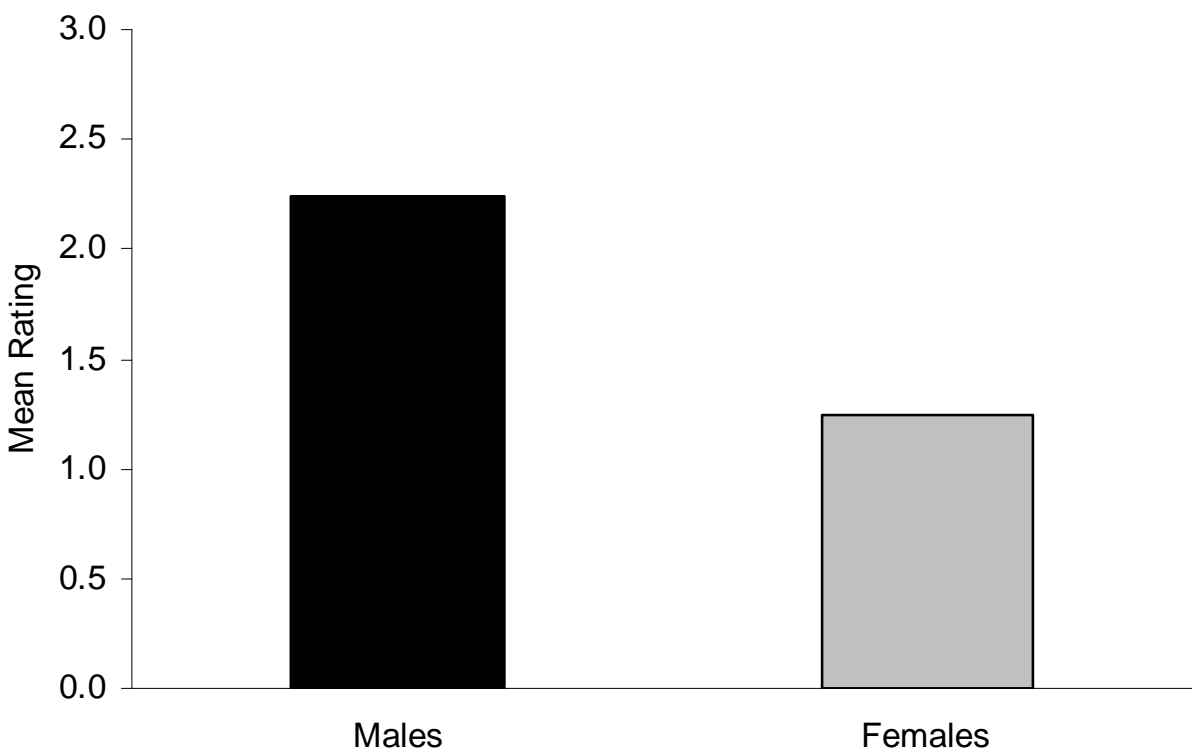

How likely would you have sex with someone who is a bad kisser?

Table 1. What factors are generally important as to what makes a kiss good (based on a five-point Likert scale of $0=$ not at all to $4=$ extremely important).

\begin{tabular}{|c|c|c|c|c|c|c|c|c|}
\hline & Sex & $N$ & Mean & $S D$ & $d f$ & $t$ & $p$ & $\eta^{2}$ \\
\hline \multirow{2}{*}{$\begin{array}{l}\text { My partner initiates kissing / is more } \\
\text { assertive }\end{array}$} & male & 69 & 2.25 & 0.88 & 248 & -1.29 & 0.199 & \\
\hline & female & 181 & 2.40 & 0.85 & & & & \\
\hline \multirow[t]{2}{*}{ My partner initiates tongue contact } & male & 69 & 2.25 & 0.88 & 248 & 1.04 & 0.298 & \\
\hline & female & 181 & 2.11 & 0.94 & & & & \\
\hline \multirow{2}{*}{$\begin{array}{l}\text { My partner lets me initiate tongue } \\
\text { contact }\end{array}$} & male & 69 & 2.35 & 0.80 & 247 & 3.37 & 0.001 & .044 \\
\hline & female & 180 & 1.92 & 0.92 & & & & \\
\hline \multirow[t]{2}{*}{ The scent of partner's body } & male & 69 & 2.81 & 0.79 & 248 & -0.85 & 0.396 & \\
\hline & female & 181 & 2.91 & 0.85 & & & & \\
\hline \multirow{2}{*}{$\begin{array}{l}\text { The amount of touching/physical } \\
\text { contact/caressing while kissing }\end{array}$} & male & 69 & 3.12 & 0.61 & 248 & 1.60 & 0.112 & \\
\hline & female & 181 & 2.96 & 0.70 & & & & \\
\hline \multirow[t]{2}{*}{ The kissing leads to sex } & male & 68 & 1.97 & 1.20 & 242 & 5.41 & 0.000 & .108 \\
\hline & female & 176 & 1.16 & 0.99 & & & & \\
\hline \multirow[t]{2}{*}{ My partner makes moaning noises } & male & 68 & 1.87 & 1.17 & 243 & 6.59 & 0.000 & .152 \\
\hline & female & 177 & 0.87 & 1.01 & & & & \\
\hline
\end{tabular}




\section{Kissing}

\section{Attractiveness and Kissing}

To assess the importance of physical appearance when making the decision to kiss someone, participants were asked to rate certain traits on a five-point Likert scale $(0=n o t$ at all important to $4=$ extremely important). A shown in Table 2, there were several sex differences. Females rated the appearance of healthy teeth as being more important than males, whereas males placed more importance on facial attractiveness, the attractiveness of the person's body, and their weight.

Table 2. How important are the following physical factors when deciding whether or not you want to kiss someone (based on a five-point Likert scale of $0=$ not at all to $4=$ extremely important).

\begin{tabular}{|c|c|c|c|c|c|c|c|c|}
\hline & Sex & $N$ & Mean & $S D$ & $d f$ & $t$ & $p$ & $\eta^{2}$ \\
\hline \multirow{2}{*}{ Healthy appearance of someone's teeth } & male & 68 & 2.60 & 0.83 & 246 & -2.86 & 0.005 & .032 \\
\hline & female & 180 & 2.92 & 0.77 & & & & \\
\hline \multirow[t]{2}{*}{ Attractiveness of someone's face } & male & 69 & 2.93 & 0.67 & 247 & 2.09 & 0.037 & .017 \\
\hline & female & 180 & 2.71 & 0.75 & & & & \\
\hline \multirow[t]{2}{*}{ Attractiveness of someone's body } & male & 69 & 2.78 & 0.68 & 247 & 3.65 & 0.000 & .051 \\
\hline & female & 180 & 2.41 & 0.75 & & & & \\
\hline \multirow[t]{2}{*}{ Attractiveness of someone's lips } & male & 67 & 2.52 & 0.73 & 245 & 0.45 & 0.650 & \\
\hline & female & 180 & 2.47 & 0.90 & & & & \\
\hline \multirow{2}{*}{ Person's weight (how heavy the person is) } & male & 69 & 2.38 & 0.96 & 246 & 2.41 & 0.016 & .023 \\
\hline & female & 179 & 2.04 & 0.98 & & & & \\
\hline \multirow[t]{2}{*}{ Person has a healthy complexion (clear skin) } & male & 69 & 2.48 & 0.85 & 246 & 1.05 & 0.293 & \\
\hline & female & 179 & 2.35 & 0.89 & & & & \\
\hline \multirow{2}{*}{ Person has soft lips } & male & 69 & 2.41 & 0.86 & 246 & -0.32 & 0.752 & \\
\hline & female & 179 & 2.45 & 0.94 & & & & \\
\hline \multirow[t]{2}{*}{ Person has full lips } & male & 68 & 2.12 & 0.80 & 245 & 1.00 & 0.318 & \\
\hline & female & 179 & 1.97 & 1.09 & & & & \\
\hline
\end{tabular}

\section{Discussion}

Our results support previous findings in showing a high incidence of kissing between romantic and/or sexual partners (Dunne, Donald, Lucke, Nilsson, Ballard, and Raphael, 1994; Youn, 1996). Out of 1,041 respondents, all aged 18 or older, only 5 individuals reported never having romantically kissed another person. Approximately 70\% of the sample acknowledged kissing 6 or more people, while $20 \%$ estimated having kissed more than 20 people. There were no sex differences in the number of kissing partners, nor were there sex differences in the age of experiencing one's first romantic kiss.

Our hypothesis that females place a greater emphasis on kissing for making mate assessments was consistent with several results. Our data show that females are more likely to base evaluations of their partners' kissing ability on chemical cues (i.e., the breath and the taste of their mouth), and for females an important physical feature in deciding whether to kiss someone was the appearance of their teeth. Kissing could provide information about a person's health and hormonal status since sebaceous glands are located in high density on the face and are regulated by sex hormones (Durham, et al, 1993; Hoshi, et al., 2002; Nicholson, 1984; Rosenberg, 2002; Service, 1998). The taste and the smell of an 


\section{Kissing}

individual's mouth can also be indicative of underlying health problems (Durham, et al., 1993; Hoshi, et al., 2002; Rosenberg, 2002; Service, 1998).

Our first hypothesis was also supported by the fact that fewer females than males were willing to have sexual intercourse without kissing their partners first. Females also felt that a male who is a bad kisser is less attractive/desirable. Previous studies have shown that during initial dating with a romantic partner, women wanted physical contact, hugging, and sensuous kissing, whereas males wanted to touch their partner's breasts and genitals (McCabe and Collins, 1984). Together these findings suggest that females place more importance on kissing, and are more reliant on kissing as a mate assessment technique. In addition to assessing the health of a prospective mate, kissing may enable females to assess her partner's level of commitment.

At the moment of a kiss, there is an exceedingly rich and complex exchange of postural, tactile, and chemical cues. As evidence for just how biologically important this exchange can be, one of us (Gallup) recently completed an unrelated survey which included the question "Have you ever found yourself attracted to someone, only to discover after kissing them for the first time that you were no longer interested?" Out of 58 male respondents, 59\% answered "yes," and 66\% of 122 female respondents also answered in the affirmative. Thus, what transpires during an initial kiss can have a profound effect on the future of that relationship. Perhaps kissing in these instances may activate evolved mechanisms that function to discourage reproduction among individuals who could be genetically incompatible.

Whereas males tended to place less importance on kissing, our prediction that they would prefer wetter kisses, more tongue contact, and open mouth kisses was confirmed. Males showed a greater preference for tongue contact and open mouth when kissing shortterm partners, and when sharing a first kiss with someone they would like to have a longterm relationship with, males wanted more tongue involvement. Males also consider a "good kiss" as one where their partner lets them initiate tongue contact. It is possible that kissing styles that maximize salivary exchange provide subtle information about a female's reproductive status since saliva and breath odor change across the menstrual cycle (Fullagar, 2003; McCann and Bonci, 2001). Because males have reduced chemosensory detection in comparison to females, they may also need greater salivary exchange in order to respond to various components in a female's saliva. In addition, male preference for salivary exchange could function to introduce substances such as hormones or proteins into women's mouths that may influence their mating psychology, and even make them more sexually receptive. Studies have shown that the mucosa membrane inside the mouth is permeable to hormones such as testosterone that are found in saliva (Dobs, Matsumoto, Wang, and Kipnes, 2004). Buccal administration of substances into the mouth mucosa circumvents hepatic first-pass and digestive degradation and provides a direct route to systemic circulation (van Eyk and van der Bijl, 2004). Paralleling vaginal lubrication in response to sexual arousal, males may also perceive increased moisture when kissing as a sign of greater sexual receptivity on the part of their partner. It is interesting to note that whereas both sexes preferred more tongue contact when kissing a long term partner, especially just before sex, when it comes to first kisses, both sexes indicated that they preferred more tongue contact with someone intended to be a short-term mate. We suspect that more tongue contact during an initial encounter may aid in mate assessment and/or function to increase arousal and likelihood to have casual sex. 


\section{Kissing}

Males were less discriminating when it comes to deciding who to kiss or who to have sex with. They were more willing to have sex with someone without kissing, to have sex with someone they are not attracted to, and agree to have sex with someone they considered to be a "bad kisser." These findings are consistent with evidence that males tend to be opportunistic maters (Symons, 1979) and further support our hypothesis that males may not place as much importance on using kissing to make mate assessments.

Male sexual attraction evolved to put a premium on female features that signal reproductive viability (Thornhill and Grammer, 1999; Scheib, Gangestad, and Thornhill, 1999). We found that males placed more emphasis on their partner's face, body, and weight as focal characteristics they use to decide whether to kiss someone. These preferences mirror the physical features that men use when selecting mating partners and/or cues for detecting a female's reproductive status (Buss, Shackelford, Kirkpatrick and Larsen, 2001; Rozin and Fallon, 1988).

Several findings support our second hypothesis that both males and females use kissing as a bonding mechanism and place more importance on kissing long-term than short-term partners. First, both sexes felt that kissing a long-term partner creates greater emotional closeness. Second, both sexes agreed that kissing after sex creates more of a bond with their long-term partner than short-term partner, and they indicated wanting to kiss their long-term partner after experiencing an orgasm more often than a short-term partner. Third, both sexes were less likely to have sex without kissing a long-term partner than a short-term partner. Our data, however, suggest that the connection between kissing and bonding may not be driven by a conscious component. The majority of males and females agreed they would not begin a relationship with someone simply because they were a good kisser.

Several findings also support our hypothesis that females appear to place a greater emphasis on kissing to induce bonding. In long-term relationships, females not only rated kissing as more important, but they indicated that kissing was important throughout a relationship, whereas males place less importance on kissing as the relationship progresses. Although one might expect males to place just as much importance on kissing over the course of a long-term relationship, our data suggest that kissing as a bonding function may be less important for males as it is to induce sexual arousal. Furthermore, females placed more importance on kissing before, during, and after sexual intercourse, regardless of whether it is with a long-term or short-term relationship. Both sexes also agreed that females are more likely to initiate kissing after sexual intercourse. This supports other findings in showing that males tend to engage in a hasty post-copulatory departure and demonstrate an emotional shift after sexual intercourse to reduce the likelihood of bonding and investment in short-term mating partners (Haselton and Buss, 2001).

Females were less likely to kiss someone they knew only wanted sex. Whereas males were more likely to have sex without kissing a short-term partner, females were equally unlikely to have sex without kissing either a short- or long-term partner. Females also indicated being more jealous than males if they caught their short-or long-term partner kissing someone else, a finding that supports previous studies showing that women are more upset by the prospect of their partner kissing someone else (Buunk and Hupka, 1987) and are more upset by the prospect of emotional infidelity (Buss, Larsen, Semmelroth, and Westen, 1992). 


\section{Kissing}

More males than females used kissing in an attempt to end a fight. Kissing as a reconciliation gesture has been observed in other primates. For instance, bonobos and common chimpanzees have been shown to kiss and embrace after fights, as an ostensible means of conflict resolution (de Waal and van Roosmalen, 1979; de Waal, 2000). Kissing is also used by female chimpanzees to acquire food from males (de Waal, 2000). In humans, there is evidence that conflict resolution is facilitated with increasing amounts of kissing (Gulledge, et al., 2003), and our data show that this may be principally maleinitiated.

In support of our third hypothesis, kissing seems to be viewed by both sexes as an activity that can increase sexual arousal and receptivity, and may facilitate the occurrence of sexual intercourse. Both males and females felt that both sexes initiate kissing before sex and view kissing before sex as more important than kissing during or after sex, whether it is with a short- or long-term partner. Furthermore, both men and women report that the ability to kiss well contributes to making someone "a good lover" (Lewis and Clift, 2001, p. 26).

Kissing styles that enhance salivary exchange are seen as a way to increase the arousal of a partner. Both sexes wanted to have more tongue contact before having sex with a long-term partner than a short-term partner. As predicted, both sexes also reported that they would be more jealous if they saw their partner kiss someone else with tongue contact, suggesting, that a tongue kiss signals intent to engage in sexual intercourse with the extrapair partner.

Overall, our data show that males feel kissing should lead to sex more often than do females. Whereas females felt there was a greater likelihood that kissing should lead to sex with a long-term partner than a short-term partner, males felt that in either instance, kissing should lead to sex. Males also categorized a "good kiss" as one that leads to sex and one where "my partner makes moaning noises," which may signal arousal and receptivity. Men rate kissing as more "erotic" than do women (Suman, 1997) and more men consider "deep kissing (French or tongue kissing)” as having sex (Pitts and Rahman , 2001 p.171).

It is important to acknowledge several limitations of our study. Our sample consisted of mainly college-aged students and these findings may not necessarily generalize to older or more heterogeneous adults. Furthermore, the functions of kissing proposed here may not be the same for those who are married and/or have children. This study is also limited by the fact that we relied on self-reports rather than direct observation or experimental manipulations and causality cannot be inferred from our analyses. Future investigations examining the incidence of mouth contact and saliva exchange in non-sexual romantic kissing situations (e.g., parent-child kissing) would also help clarify the distinction between different categories of kissing.

Nonetheless, this study provides evidence that romantic kissing may have evolved as an adaptive courtship strategy that functions as a mate-assessment technique, a means of initiating sexual arousal and receptivity, and a way of maintaining a bonded relationship. While both sexes participate in the adaptive benefits of kissing, we found sex differences when considering the pursuit of short- versus long-term mating strategies. We suspect that overall, women place a greater importance on kissing not only to make more judicious mate assessments, but for those in committed relationships kissing is used (wittingly or not) to update, monitor, and assess the status of their partner's continuing commitment (or lack thereof) to the relationship. Males tend to employ romantic kissing as a means of increasing 


\section{Kissing}

sexual receptivity and gaining sexual access, to affect conflict resolution, and to possibly monitor the fertility of his mate.

Acknowledgements: We thank Allegra R. Edelman, Amy J. LeFevre, Jennifer A. Davis, Franco Dispenza, R. Nathan Pipitone, and Andrew C. Gallup for help in data collection.

\section{Received 30 April 2007; Revision submitted 07 August 2007; Accepted 13 August 2007}

\section{References}

Abbey, A., McAuslan, P., Zawacki, T., Clinton, A., and Buck, P. (2001). Attitudinal, experiential, and situational predictors of sexual assault perpetration. Journal of Interpersonal Violence, 16, 784-807.

Arnold, K.A. and Barling, J. (2003). Prostitution: An illustration of occupational stress in "dirty" work. In: M. Dollard and A. Winefield (Eds.), Occupational Stress in the Service Professions. (pp. 261-280). New York: Taylor and Francis.

Brewis, J. and Linstead, S. (2000). "The worst thing is the screwing": Consumption and the management of identity in sex work. Gender, Work, and Organization, 7, 84-97.

Buss, D.M., Larsen, R., Semmelroth, J., and Westen, D. (1992). Sex differences in jealousy: Evolution, physiology, and psychology. Psychological Science, 3, 251255.

Buss, D.M. and Schmitt, D.P. (1993). Sexual strategies theory: An evolutionary perspective on human mating. Psychological Review, 100, 204-232.

Buss, D.M., Shackelford, T.K. Kirkpatrick, L.A., and Larsen, R.J. (2001). A half century of American mate preferences. Journal of Marriage and Family, 63, 491-503.

Buunk, B. and Hupka, R. (1987). Cross-cultural differences in the elicitation of sexual jealousy. The Journal of Sex Research, 23, 12-22.

Carter, C.S. (1992). Oxytocin and sexual behavior. Neuroscience and Biobehavioral Reviews, 16, 131-144.

Chirstopher, F.S. (1988). An initial investigation into a continuum of premarital sexual pressure. The Journal of Sex Research, 25, 255-266.

deWaal, F. (2000). Primates: A natural heritage of conflict resolution. Science, 289, 586590.

deWaal, F. and van Roosmalen, A. (1979). Reconciliation and consolidation among chimpanzees. Behavioral Ecology and Sociobiology, 5, 55-66.

Dobs, A.S., Matsumoto, A.M., Wang, C., and Kipnes, M.S. (2004). Short-term pharmacokinetic comparison of a novel testosterone buccal system and a testosterone gel in testosterone deficient men. Current Medical Research and Opinion, 5, 729-738.

Doty, R.L., Shaman, P., Applebaum, S.L., Giberson, R., Siksorski, L., and Rosenberg, L. (1984). Smell identification ability: Changes with age. Science, 226, 1441-1443.

Dunne, M.P., Donald, M., Lucke, J., Nilsson, R., Ballard, R., and Raphael, B. (1994). Agerelated increase in sexual behaviors and decrease in regular condom use among adolescents in Australia. International Journal of STD and AIDS, 5, 41-47. 


\section{Kissing}

Durham, T.M., Malloy, T., and Hodges, E.D. (1993). Halitosis: Knowing when "bad breath” signals systemic disease. Geriatrics, 48, 55-59.

Eibl-Eibesfeldt, I. (1970). Love and Hate: On the Natural History of Behavior Patterns. New York: Methuen.

Fisher, H. (1983). The Sex Contract. New York: Quill.

Fisher, H. (1992). Anatomy of Love: A Natural History of Monogamy, Adultery, and Divorce. New York: W.W. Norton

Ford, C.S. and Beach, F.A. (1951). Patterns of Sexual Behavior. New York: Harper and Row.

Fullagar, R. (2003). Kiss me. Nature Australia, 27, 74-75.

Geer, J., Heiman, J., and Leitenberg, H. (1984). Human sexuality. Englewood Cliffs, NJ: Prentice Hall.

Goodchilds, J.D. and Zellman, G.L. (1984). Sexual signaling and sexual aggression in adolescent relationships. In: N. Malamuth and E. Donnerstein, (Eds.), Pornography and Sexual Aggression (pp. 233-243). Orlando: Academic Press.

Gulledge, A.K., Gulledge, M.H., and Stahmann, R.F. (2003). Romantic physical affection types and relationship satisfaction. The American Journal of Family Therapy, 31, 233-242.

Hallett, R., Haapanen, L.A., and Teuber, S.S. (2002). Food allergies and kissing. New England Journal of Medicine, 346, 1833-1834.

Haselton, M.G. and Buss, D.M. (2001). The affective shift hypothesis: The functions of emotional changes following sexual intercourse. Personal Relationships, 8, 357369.

Hoshi, K., Yamano, Y., Mitsunaga A., Shimizu S., Kagawa J., and Ogiuchi, H. (2002). Gastrointestinal diseases and halitosis: association of gastric Helicobacter pylori infection. International Dental Journal, 52, 207-211.

Koss, M. (1988). Hidden rape: Sexual aggression and victimization in a national sample in higher education. In: A.W. Burgess (Ed.), Rape and Sexual Assault (pp. 3-25), New York: Garland.

Lewis, J. and Clift, S. (2001). Living for Tomorrow: Project About Young People's Attitudes to Men, Women, and Sex. Oslo: The Nordic Institute for Women's Studies and Gender Research.

McCabe, M.P. and Collins, J.K. (1984). Measurement of depth of desired and experienced sexual involvement at different stages of dating. Journal of Sex Research, 20, 377390.

McCann, A. and Bonci, L. (2001). Maintaining women's oral health. Dental Clinical North America, 45, 571-601.

Montagna, W. and Parakkal, P.F. (1974). The Structure and Function of Skin, New York: Academic Press.

Muehlenhard, C.L. and Cook, S.W. (1988). Men's self-reports of unwanted sexual activity. The Journal of Sex Research, 24, 58-72.

Nicholson, B. (1984). Does kissing aid human bonding by semiochemical addiction? British Journal of Dermatology, 111, 623-627.

Pause, B.M., Sojka, B., Krauel, K., Fehm-Wolfsdorf, G., and Ferstl, R. (1996). Olfactory information processing during the course of the menstrual cycle. Biological Psychology, 44, 31-54. 


\section{Kissing}

Pitts, M. and Rahman, Q. (2001). Which behaviors constitute "having sex" among university students in the UK? Archives of Sexual Behavior, 30, 169-176.

Rosenberg, M. (2002). The science of bad breath. Scientific American, 286, 72-78.

Rozin, P. and Fallon, A. (1988). Body image, attitudes to weight, and misperceptions of figure preferences of the opposite sex: A comparison of men and women in tow generations. Journal of Abnormal Psychology, 97, 342-345.

Scheib, J.E., Gangestad, S.W., and Thornhill, R. (1999). Facial attractiveness, symmetry, and cues of good genes. Proceedings of the Royal Society of London B, 266, 19131917.

Service, R. (1998). Breathalyzer device sniffs for disease. Science, 281, 1431.

Smith, R. L. (1984). Human sperm competition. In: R.L. Smith (Ed.). Sperm Competition and the Evolution of Mating Systems (pp. 601-659). New York: Academic Press.

So-Kum Tang, C., Critelli, J.W., and Porter, J. (1995). Sexual aggression and victimization in dating relationships among Chinese college students. Archives of Sexual Behavior, 24, 47-53.

Suman, H.C. (1997). Attributes of gazing behaviour and physical contact in interpersonal relationship. Journal of Personality and Clinical Studies, 13, 93-98.

Symons, D. (1979). The Evolution of Human Sexuality. New York, NY, USA: Oxford University Press.

Thornhill, R., and Grammer, K. (1999). The body and face of woman: One ornament that signals quality? Evolution and Human Behavior, 20, 105-120.

Tonzetich, J., Preti, G., and Huggins, G. (1978). Changes in concentration of volatile sulfur compounds of mouth air during the menstrual cycle. Journal of International Medical Research, 6, 245-256.

Trivers, R. (1972). Paternal investment and sexual selection. In: B. Campbell (Ed.), Sexual Selection and the Descent of Man (pp. 136-179). New York: Aldine de Gruyter.

Tucker, R.K., Marvin, M.G., and Vivian, B. (1991). What constitutes a romantic act? An empirical study. Psychological Reports, 69, 651-654.

van Eyk, A.D. and van der Bijl, P. (2004). Comparative permeability of various chemical markers through human vaginal and buccal mucosa as well as porcine buccal and mouth floor mucosa. Archives of Oral Biology, 49, 387-392.

Waldner, L.K., Vaden-Goad, L., and Sikka, A. (1999). Sexual coercion in India: An exploratory analysis using demographic variables. Archives of Sexual Behavior, 28, 523-538.

Youn, G. (1996). Sexual activities and attitudes of adolescent Koreans. Archives of Sexual Behavior, 25, 629-643.

Zahavi, A. and Zahavi, A. (1997). The handicap principle: A missing piece of Darwin's puzzle. New York: Oxford University Press. 